2. To: (Receiving Organization)

Distribution

5. Proj./Prog./Dept/Div.:

HANDI 2000 INTEGRATION

8. Originator Remarks:

KEY WORDS: HANDI 20000

Business Management

Configuration Management Bo Relave un

11. Receiver Remarks:
N/A

7. Purchase Order No:

$\mathrm{N} / \mathrm{A}$

9. Equip./Comporient No.:

N/A

10. System/Bidg./Facility:

$\mathrm{N} / \mathrm{A}$

12. Major Assm. Dwg. No.

$\mathrm{N} / \mathrm{A}$

13. Permit/Permit Application No.:

$\mathrm{N} / \mathrm{A}$

14. Required Response Date:

N/A

\begin{tabular}{|c|c|c|c|c|c|c|c|c|}
\hline & & & & & & & & \\
\hline 15. & & DATA TRA & NSMITTE & & (F) & (G) & (H) & (l) \\
\hline $\begin{array}{l}\text { (A) } \\
\text { Item } \\
\text { No. }\end{array}$ & (B) Document/Drawing No. & $\begin{array}{l}\text { (C) Sheet } \\
\text { No. }\end{array}$ & (D) Rev. & (E) Title or Description of Data Transmitted & $\begin{array}{l}\text { Approval } \\
\text { Desig- } \\
\text { nator }\end{array}$ & $\begin{array}{c}\text { Reason } \\
\text { for Trans- } \\
\text { mittal }\end{array}$ & $\begin{array}{c}\text { Origi- } \\
\text { nator } \\
\text { Dispo- } \\
\text { stion }\end{array}$ & $\begin{array}{l}\text { Receiv- } \\
\text { er } \\
\text { Dispo- } \\
\text { sition }\end{array}$ \\
\hline 1 & $\mathrm{HNF}-2583$ & $\mathrm{~N} / \mathrm{A}$ & REV 0 & sftware Config. Mgmt. Plan & $N / A$ & 2 & I & \\
\hline & & & & & & & & \\
\hline & & & & & & & & \\
\hline & & & & & & & & \\
\hline & & & & & & & & \\
\hline & & & & & & & & \\
\hline & & & & & & & & \\
\hline
\end{tabular}

16.

Approval Designator $(F)$

$E, S, Q, D$ OR N/A (See WHC-CM-3-5, Sec. 12.7)

\begin{tabular}{l|l} 
& \\
1. Approval \\
2. Release \\
3. Information
\end{tabular}

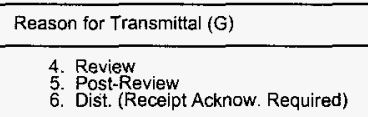

.
SIGNATURE/DISTRIBUTION

(See Approval Designator for required signatures)

17.

\begin{tabular}{|c|c|lc|}
\hline $\begin{array}{c}\text { Rea- } \\
\text { Ron }\end{array}$ & $\begin{array}{c}(\mathrm{H}) \\
\text { Disp. }\end{array}$ & (J) Name (K) Signature (L) Date (M) MSIN \\
\hline 2 & 1 & Design Authority Sandra Evosevi ch G/ \\
\hline & & Design Agent \\
\hline & & Cog. Eng. \\
\hline & & Cog. Mgr. \\
\hline & & QA \\
\hline & & Safety \\
\hline 18. & & Env. \\
\hline
\end{tabular}

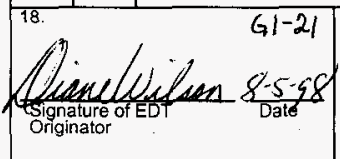

18.

$\mathrm{N} / \mathrm{A}$

Authorized Representative for Receiving Organization

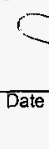

20.

\begin{tabular}{|c|c|c|}
$\begin{array}{c}\text { Rea- } \\
\text { Roa } \\
\text { son }\end{array}$ & $\begin{array}{c}(\mathrm{H}) \\
\text { Disp. }\end{array}$ & \\
\hline & & \\
\hline & & \\
\hline
\end{tabular}

(J) Name

Central Filew 81-07
Disposition $(H)$ \& (I)

1. Approved

2. Approved w/comment

Disapproved w/comment

4. Reviewed no/comment

5. Reviewed w/comment

6. Receipt acknowledged 


\section{Software Configuration Management Plan}

Diane wilson, Fluor Daniel Hanford Co.

2355 Stevens, MSN GI-22

Richland, WA 99352

U.S. Department of Energy Contract DE-AC06-96RL13200

EDT/ECN: 625352

UC: 900

Org Code: SL650000

B\&R Code: EW7001000

Charge Code: HANF6800, YBPME

Total Pages: 28

Key Words: HANDI 2000, BUSINESS MANAGEMENT, Configuration Management

Abstract: The Software Configuration Management Plan (SCMP) describes the configuration management and control environment for HANDI 20000 for the PP and PS software as well as any custom developed software. This plan establishes requirements and processes for uniform documentation control, system change control, systematic evaluation and coordination of HANDI 2000. This SCMP becomes effective as of this document's acceptance and will provide guidance through implementation efforts...

TRADEMARK DISCLAIMER. Reference herein to any specific commercial product, process, or service by trade name, trademark, manufacturer, or otherwise, does not necessarily constitute or imply its endorsement, recommendation, or favoring by the United States Government or any agency thereof or its contractors or subcontractors.

Printed in the United States of America. To obtain copies of this document, contact: Document Control Services, P.O. Box 950, Mailstop H6-08, Richland WA 99352, Phone (509) 372-2420; Fax (509) 376-4989.

Passpost is a trademark of Indus Corp. PeopleSoft is a trademark of Indus corp.

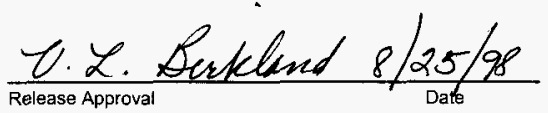

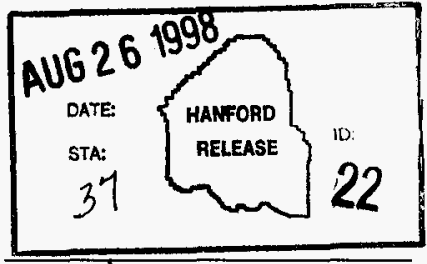

Release Stamp 


\title{
SOFTWARE CONFIGURATION MANAGEMENT PLAN
}

\author{
FOR
}

\section{HANDI 2000}

\section{BUSINESS MANAGEMENT SYSTEM}

Prepared by: Sandra Evosevich, LMSI Software Engineer

Terri M. Lutter, LMSI Software Engineer

Prepared for: Fluor Daniel Hanford

Approved by:

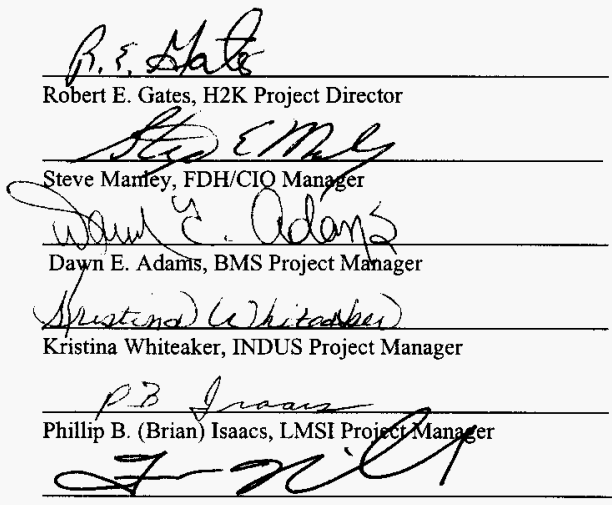

Ted R. Neville, LMSI/SD\&I Manager

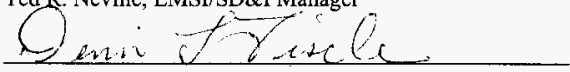

Dennis L. Fischer, LMSI CM/QA Manager
$8 / 3 / 98$

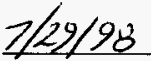

Date

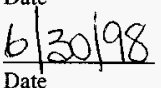

$\frac{-1 / 7 / 98}{\text { Date }}$

$6 / 30 / 98$

Date

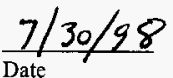

$\frac{8 / 3 / 98}{\text { Date }}$ 


\section{TABLE OF CONTENTS}

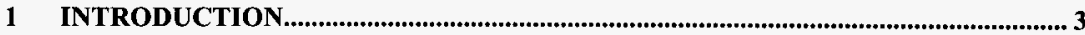

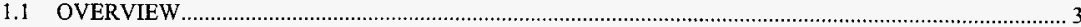

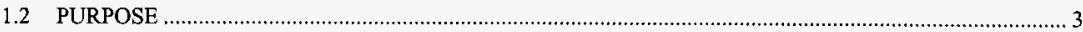

1.3 SCOPE

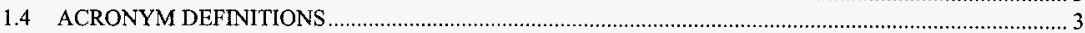

1.5 TERMS

1.6 REFERENCES

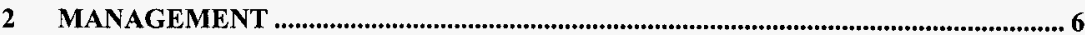

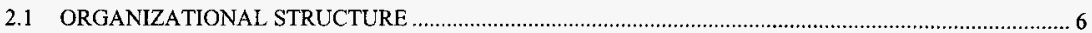

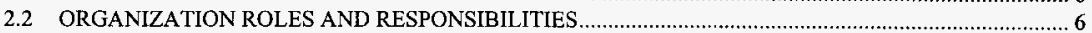

2.3 PERSONNEL ROLES AND RESPONSIBILITIES .....................................................................

2.4 HANDI 2000 SOFTWARE CHANGE CONTROL BOARDS …………………....................................

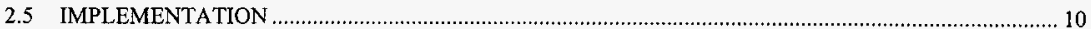

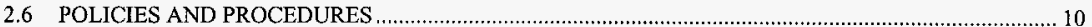

3 SOFTWARE CONFIGURATION MANAGEMENT ACTIVITIES............................... 11

3.1 CONFIGURATION IDENTIFICATION ……………………………………………………………... 11

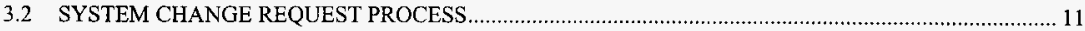

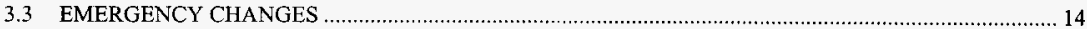

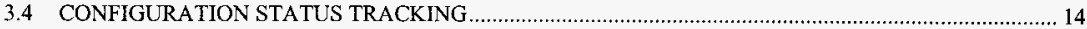

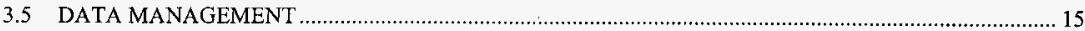

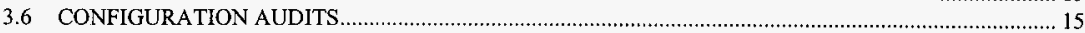

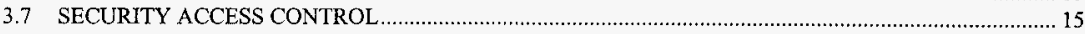

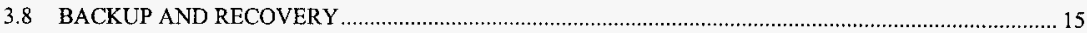

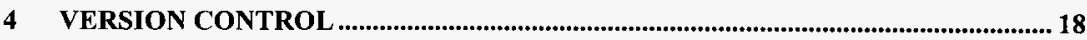

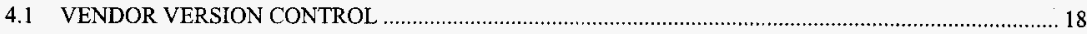

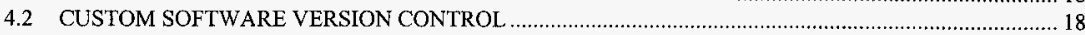

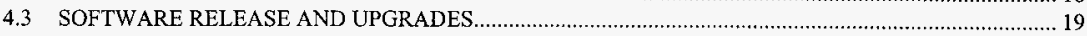

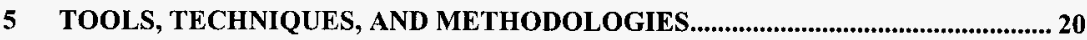

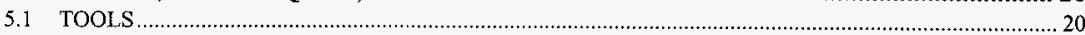

5.2 TECHNIQUES

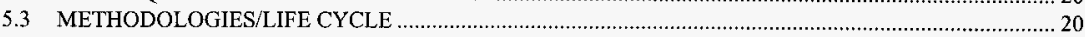

6 DATA/RECORDS COLLECTION AND RETENTION N................................................. 21

7 APPENDIX A VERSION DESCRIPTION DOCUMENT FORMAT …....................... 22

8 APPENDIX B HANDI 2000 CUSTOMIZATION GUIDELINES................................. 23

9 APPENDIX C SCR - SYSTEM CHANGE REQUEST FORM INSTRUCTIONS..... 25

10 APPENDIX D HANDI 2000 BOARD MEMBERS........................................................ 28 


\section{INTRODUCTION}

\subsection{OVERVIEW}

The Hanford Data Integration 2000 (HANDI 2000) Project will result in an integrated and comprehensive set of functional applications containing core information necessary to support the Project Hanford Management Contract (PHMC). It is based on the Commercial-Off-The-Shelf (COTS) product solution with commercially proven business processes. The system will reduce the number of legacy systems maintained today and absorb key systems identified that have Year 2000 issues. This includes systems that support finance, supply and chemical management/Material Safety Data Sheet (MSDS), human resources and payroll activities on the Hanford Site. The PassPort (PP) software is an integrated application for Accounts Payable, Contract Management, Inventory Management, Purchasing and MSDS. The PeopleSoft (PS) software is an integrated application for General Ledger, Project Costing, Human Resources, Payroll, Benefits, and Training. The implementation of this set of products, as the first deliverable of the HANDI 2000 Project, is referred to as Business Management System (BMS) and Chenical Management/MSDS.

\subsection{PURPOSE}

The Software Configuration Management Plan (SCMP) describes the configuration management and control environment for HANDI 2000 for the PP and PS software as well as any custom developed software. This plan establishes requirements and processes for uniform documentation control, system change control, systematic evaluation, and coordination of HANDI 2000. This SCMP becomes effective as of this document's acceptance and will provide guidance through implementation efforts and, as a "living document", will support the operation and maintenance of the HANDI 2000 systems.

\subsection{SCOPE}

The SCMP covers software configuration management, configuration identification, configuration change control, configuration status tracking, and configuration audits. The SCMP applies to the PP, PS, and custom application software and supporting documentation of HANDI 2000. The SCMP and associated procedures apply to all BMS and MSDS modules, and external system interfaces, as well as future HANDI 2000 modules. Excluded are vendor software products required to maintain the system servers, workstations, and telecommunications equipment in operational status.

\subsection{ACRONYM DEFINITIONS}

\begin{tabular}{|l|l|}
\hline \multicolumn{1}{|c|}{ Acronym } & \multicolumn{1}{c|}{ Definition } \\
\hline ANSI/IEEE & $\begin{array}{l}\text { American National Scientific Institute/Institute of Electrical and Electronics } \\
\text { Engineers }\end{array}$ \\
\hline BMS & Business Management System \\
\hline CIO & Chief Information Officer \\
\hline COTS & Commercial Off The Shelf \\
\hline CCB & Change Control Board \\
\hline DOE-RL & Department of Energy-Richland, Washington \\
\hline FDH & Fluor Daniel Hanford \\
\hline HANDI 2000 & Hanford Data Integration (Year 2000 compliant) \\
\hline HLAN & Hanford Local Area Network \\
\hline INDUS & Indus International, Inc. \\
\hline IRM & Information Resource Management \\
\hline LMSI & Lockheed Martin Services, Incorporated \\
\hline LMSI OSSP & Lockhed Martin Services, Incorporated Organization Standard Software \\
\hline
\end{tabular}


HANDI 2000

DOC ITEM: Software Configuration Management Plan

HNF- 2583, REV 0

DATE: $05 / 19 / 98$

PAGE: 4 of 28

\begin{tabular}{|l|l|}
\hline \multicolumn{1}{|c|}{ Acronym } & \multicolumn{1}{|c|}{ Definition } \\
\hline MSDS & Practices \\
\hline PHMC & Material Safety Data Sheet \\
\hline PP & Project Hanford Management Contract \\
\hline PRRB & PassPort software \\
\hline PS & Production Readiness Review Board \\
\hline SCM & PeopleSoft software \\
\hline SCMP & Software Configuration Management \\
\hline SCR & Software Configuration Management Plan \\
\hline SCR/PR & System Change Request \\
\hline SEI/CMM & System Change Request/Problem Report \\
\hline TRB & Software Engineering Institute/Capability Maturity Model \\
\hline VDD & Technical Review Board \\
\hline
\end{tabular}

\subsection{TERMS}

Baseline: A bounded set of uniquely identified Configuration Items, which constitute the software product baseline either from an overall development or a COTS product. The software product baseline thereafter serves as the basis for further development of the software product.

Configuration Item (C): The basic unit of software configuration management. This could be any life cycle document, source code module(s), various libraries, utilities etc., which in the aggregate comprise "the system".

COTS Customization: Any approved change to a COTS baseline software to satisfy a specific need that can not be met by changing system options, user options, or business processes not mandated by law or policy above the level of DOE-RL-RL. Reference APPENDIX B, HANDI 2000 Customization Guidelines.

HANDI 2000 Change Control Board: The primary purpose of the CCB, is to review and direct the HANDI 2000 business and funding requirements, associated policies for the site, and retain final authority to approve/disapprove System Change Requests.

HANDL 2000 Production Readiness Review Board: The primary purpose of the PRRB serves to ensure changes to, or implementation of new Hanford systems will not adversely impact any other production system and/or the Hanford Local Area Network (HLAN).

HANDI 2000 Project: The Hanford Data Integration Year 2000 Project is an integrated comprehensive set of functional applications containing core information needed to support the Project Hanford Management Contract.

HANDI 2000 Technical Review Board: The primary purpose of the Technical Review Board is to ensure FDH and LMSI standards for software development and controls are upheld during any system change or implementation.

Production: Pertaining to the status of a given system once it has entered the operation and maintenance phase. Production status is granted after customer acceptance and implementation is complete.

Project Management Organization: The FDH organization that has ownership responsibility for the software, with LMSI technical support. 
HANDI 2000

DOC ITEM: Software Configuration Management Plan

HNF- 2583, REV 0

DATE: $05 / 19 / 98$

System Change Request (SCR): The SCR document specifies changes required to resolve a system problem, add, modify, or delete functionality, or improve performance. An SCR is the initial identification of proposed changes to systems and must be agreed to by the customer prior to review by the TRB or commencement of change implementation activities.

Software Configuration Management: A set of management disciplines within the context of the system engineering process that applies technical and administrative direction and surveillance. It identifies and documents the functional and physical characteristics of a product, controls changes to those characteristics, and records and reports on the change processing and implementation.

\subsection{REFERENCES}

ANSI/IEEE Std 828-1990

ANSI/IEEE Std 1042-1987

SEI/CMM

HNF-1984

HNF -2584

HNF -2585

HNF-2858

HNF-2859

HNF-2712

HNF-2639

HNF-2795

HNF-PRO-210

HNF-PRO-214

HNF-PRO-215

HNF-PRO-222

HNF-PRO-231

HNF-PRO-244

LMSI OSSP

LMSI OSSP

LMSI OSSP

LMSI OSSP

LMSI OSSP

LMSI OSSP

FDH Contracts

APPENDIX A

APPENDIX B

APPENDIX C

APPENDIX D
IEEE Standard for Software Configuration Management Plans IEEE Guide to Software Configuration Management Software Engineering Institute/Capability Maturity Model

Finance and Supply Project Execution Plan

Region and Database Management Procedure Data Management Plan

Backup and Recovery Plan for HANDI 2000 Software

Disaster Recovery Plan for HANDI 2000 Hardware and Software

Security Administration Plan

Release and Upgrade Procedure

Production Rollout Plan

Records Management Program

Record Inventory and Disposition, Schedules

Records Storage, Retrieval, and Destruction

Quality Assurance Records

Records Schedules

Engineering Data Transmittal Requirements

Software Configuration Management Plan

Production Readiness Review Board

Cost Estimating

Code Walkthroughs

Peer Review

COTS Lifecycle

MJC-SBB-A346022, 09/10/98 and G956631J73, 03/31/98.

Version Description Document

HANDI 2000 Customization Guidelines

System Change Request Process Form

HANDI 2000 Board Members 


\section{MANAGEMENT}

\subsection{ORGANIZATIONAL STRUCTURE}

Fluor Daniel Hanford Site Planning and Integration is the sponsoring organization for HANDI 2000 under the PHMC contract. Reference HNF-1984, Finance and Supply Project Execution Plan for HANDI 2000 Project Organization information.

\subsection{ORGANIZATION ROLES AND RESPONSIBILITIES}

\subsubsection{FLUOR DANIEL HANFORD CIO ORGANIZATION}

- Establish and communicate PHMC Information Management policy

- Broadcast HANDI 2000 approved standards

- Communicate approved changes for current site standards

- Arbitrate resolution of HANDI 2000 data issues impacting Department of Energy-Richland, Washington (DOERL) and Site Contractors

\subsubsection{FLUOR DANIEL HANFORD BUSINESS SYSTEMS ORGANIZATIONS}

- FDH Finance organizations are responsible for the HANDI 2000 Financial modules, financial business processes, as well as financial data and information.

- FDH Acquisition and Chemical Management organizations are responsible for the HANDI 2000 Supply modules, acquisition and supply business processes as well as supply data and information.

- The FDH Personnel Service organization is responsible for the HANDI 2000 Human Resource modules, human resource business processes, as well as human resource data and information.

- The FDH Training organization is responsible for the HANDI 2000 Training module, training business processes, as well as training data and information.

- The FDH Personnel Accounting organization is responsible for the HANDI 2000 Payroll module, payroll business processes, as well as payroll data and information.

\subsubsection{LOCKHEED MARTIN SERVICES, INCORPORATED}

- Provide the system technical staff for the HANDI 2000 Project

- Responsible for the HANDI 2000 software and hardware maintenance and operation

- Lifecycle support the HANDI 2000 business systems as required by FDH

\subsubsection{INDUS INTERNATIONAL, INCORPORATED}

Indus International, Inc. is the focal point for the PP and PS software integration. This contractor shall ensure that the integrated products are comprised of the appropriate vendor software release levels, and are ready for production installation, and will fulfill any and all contractual obligations.

\subsubsection{INTERNAL AUDIT}

- FDH Internal Audit is responsible for providing independent review of all financial, managerial, and internal control aspects of PHMC Operations. 


\subsection{PERSONNEL ROLES AND RESPONSIBILITIES}

Software Configuration Management will be a collaborative effort between FDH, LMSI, and INDUS International personnel. The primary responsibility of assuring configuration control is met belongs to the FDH system owners. Reference HNF-1984, Finance and Supply Project Execution Plan for HANDI 2000 Project roles and responsibilities.

The major roles and responsibilities are as follows:

\subsubsection{PROJECT DIRECTOR}

- Responsible for clarification of project needs and requirements

- Provide authority and interface with FDH, LMSI, and COTS personnel pertaining to unresolved issues

- As a member of the HANDI 2000 Change Control Board, represents business processes and assesses any impacts to those processes based on submitted change request(s)

\subsubsection{PROJECT MANAGER}

- Ensure the functional and technical staff is available for the support and maintenance of HANDI 2000

- Ensure the SCR process is employed/used in all software enhancement, maintenance, and application activities

- Participate in the analysis of an SCR to determine estimates of time, resources, system impact and business impact

- Determine recommended SCR/maintenance work groupings constituting version updates and/or new versions of software and documentation.

- Participate on the HANDI 2000 Technical Review Board (TRB) for review and recommendations of SCRs to the Change Control Board (CCB)

- Responsible for coordinating all approved modifications and enhancements to the system.

- Coordinate peer review for coding and system testing

- Coordinate availability and use of users as system testers with functional leads

- Conduct functional leads review and approval of test results

\subsubsection{FUNCTIONAL LEAD}

- Verify that all changes adhere to the test criteria and meet the intent of the SCR

- Monitor and report the status of SCR

- Assign SCR numbers and maintain the SCR log

- Communicate change requests to the TRB through the use of an SCR

- Participate in creation of overall test process definition and scripts

- Perform tests required to substantiate that the change is performing as specified

- Coordinate implementation of the SCR with the HANDI 2000 Production Readiness Review Board (PRRB)

\subsubsection{USER REPRESENTATIVE}

- Participate in testing SCR

- Participate in verifying and recording system test results

\subsubsection{INDUS INTEGRATION VENDOR}

- INDUS will work to the work scope out lined in their contracts. Reference FDH contracts MJC-SBB-A346022, 09/10/97 and G956631/J73, 03/31/98. 


\subsubsection{SOFTWARE ENGINEERS/BUSINESS ANALYSTS}

- Participates on the HANDI 2000 Technical Review Board

- Participate in the estimates for hours, cost, and schedule for a SCR

- Maintain the HANDI 2000 application software and supporting documentation associated with changes

- Work approved SCRs

- Assist process owners in the development of test plans to verify requested modifications perform as defined

- Perform Unit Testing and Integration Testing on changes to ensure they are error free and meet the criteria defined in the applicable SCR

- Serve as technical consultants relative to any HANDI 2000 technical issues

- Interface with the organization responsible for the Hanford Local Area Network (HLAN) and any network issues relative to the HANDI 2000 and Data Center operations

- Assists FDH Project Manager with the SCR implementation preparation for the PRRB

- Plan for and implement commercial product version upgrades and maintenance releases

- Document system changes and maintain a history of the changes

\subsubsection{DATABASE ADMINISTRATOR}

- Participates or have representation on the HANDI 2000 Technical Review Board

- Participate in the estimates for hours, cost, and schedule for a SCR

- Serve as technical consultants relative to any HANDI 2000 technical issues

- Interface with the organization responsible for the Hanford Local Area Network (HLAN) and any network issues relative to the HANDI 2000 and Data Center operations

- Create the databases

- Control the databases

- Setup operational system and database level security

\subsubsection{DATA ADMINISTRATOR}

- Management of documentation configuration control

- Interface with the FDH CIO organization

- Participate in data issue resolution

- Focal point for coordination and control of data integrity

- Provide input on long term data/information planning/needs

- Provide input for data archival and retrieval

- Establish standards and guidelines for data naming conventions, technical nomenclature, and integration

- Responsible for the data management tool set (Glossary of Terms, Data Dictionary, INDUS DM tool, Data Model(s), etc.)

\subsubsection{OPERATIONS ADMINISTRATOR}

- Creates production operational test process definitions and procedures

- Creates production network and operational test environment

- Performs production operational testing

- Performs production backup and recovery processes

- Monitors production system performance 


\subsection{HANDI 2000 SOFTWARE CHANGE CONTROL BOARDS}

There are three boards involved concerning software change control. When a System Change Request or a Problem Report (SCR/PR) is generated, the first board to review the SCR/PR is the HANDI 2000 Technical Review Board. After the Technical Review Board ensures the criteria have been met, the SCR with recommendations are forwarded to the HANDI 2000 Change Control Board. The Change Control Board retains the authority to approve/disapprove the SCR. If the SCR is approved, and the work is complete the Production Readiness Review Board (PRRB) has the responsibility to approve/disapprove implementation. Reference APPENDIX D, HANDI 2000 Board Members

\subsubsection{HANDI 2000 TECHNICAL REVIEW BOARD}

The primary purpose of the Technical Review Board (TRB) is to ensure FDH and LMSI standards for software development and controls are upheld during any system change or implementation. There are representatives from DOE-RL, FDH, LMSI and INDUS. When the TRB is satisfied the change package has met the criteria set forth below, it is forwarded to the Change Control Board for action. The TRB forwards the package with a recommendation for each request. The TRB shall review the SCR(s) when the initial estimate reveals a change in work scope or cost to the customer. The TRB examines the SCR(s) with the following objectives:

- Ensure business needs are clearly documented

- Ensure requested change is clearly stated

- Ensure costs and impacts are well documented (including potential "Accounting Changes" and associated program impacts)

- Ensure alternatives have been adequately explored

- Ensure appropriate configuration management and quality assurance activities were planned

- Ensure dollar estimates provided were obtained through appropriate channels

- Ensure estimated man hours are reasonable

The TRB will also review the SCR just prior to implementation to determine if:

- Ensure planned activities were accomplished

- Ensure SCR documentation is complete

- Ensure unit tests were comprehensive

- Ensure unit and acceptance test environments were as accurate as possible

- Ensure unit and acceptance test plans were comprehensive

\subsubsection{HANDI 2000 CHANGE CONTROL BOARD}

The primary purpose of the CCB, is to review and direct the HANDI 2000 business and funding requirements, associated policies for the site, and retain final authority to approve/disapprove System Change Requests. The members that comprise this board are representatives from DOE-RL and FDH and will meet as required. The CCB reviews the requested changes with the following objective:

- Evaluate whether or not the need justifies an action

8 Concur that alternatives were adequately evaluated

- Consider alternatives beyond the scope and control of the technical review team

- Determine whether or not the need justifies the impact of making the change

- Approve/disapprove the SCR 


\subsubsection{HANDI 2000 PRODUCTION READINESS REVIEW BOARD}

The primary purpose of the PRRB serves to ensure changes to, or implementation of new Hanford systems will not adversely impact any other production system and/or the Hanford Local Area Network (HLAN). The representatives on this board are from FDH and LMSI and will meet as required. This board reserves the right to deny implementation approval to any individual, team, or department, which cannot demonstrate that adequate preparation has been accomplished. Not all of the items listed below may apply to all changes. Reference LMSI OSSP Production Readiness Review Board.

- Acceptance test plan is complete

- Communications plan to conduct intergroup coordination with network administrators is addressed

- Identify the vehicle and responsible part for alerting end users to pending modifications to their system and an indication of down time if applicable

- Coordinate change with LMSI Customer Technical Service, and if appropriate, conduct specialized training to enable customer service to better support the customer and end-user

- Adequate planning is in place to restore systems to their prior implementation configuration in the event of an unexpected failure

- Verification that proper communication with external and internal data systems have been accomplished and the system is prepared to send or receive a modified or new file

\subsection{IMPLEMENTATION}

The LMSI software engineers, database administrators, and operations administrators establish the baseline of a configuration item. It will be documented in the SCR and/or COTS documentation. The remainder, of the project configuration items, is turned over to LMSI database administrator and/or the operations administrator immediately prior to implementation. The LMSI software engineers, database administrators, and operations administrators, with support from the COTS representative, have the responsibility for defining, with the initial Version Description Document (VDD), the first baseline for the system. Once established, the VDD is the responsibility of the LMSI organization and is updated based on changes to the system via the SCR process. Reference HNF-2795, Production Rollout Plan.

\subsection{POLICIES AND PROCEDURES}

The SCMP has been developed using the standards documented in the American National Scientific Institute/Institute of Electrical and Electronic Engineers (ANSI/IEEE), Software Engineering Institute/Capability Maturity Model (SEI/CMM), Hanford Procedures (HNF-PRO), and Lockheed Martin Services, Incorporated Organization Standard Software Practices (LMSI OSSP) document directives referenced earlier as a guideline. However, the FDH and LMSI organization reserve the right to modify procedures as needed to ensure the integrity of all configuration management baselines. Specific procedures for performing the operational maintenance SCM activities are defined in the LMSI OSSP controlled documents. 


\section{SOFTWARE CONFIGURATION MANAGEMENT ACTIVITIES}

\subsection{CONFIGURATION IDENTIFICATION}

All items, which make up a given system, must be uniquely identified and listed in the Version Description Document ( $A P P E N D I X A)$. These configured items include life cycle documentation, software code modules, application libraries, executable libraries, operating system utilities, COTS products, selected data, and other elements of the system which impact the ability to re-create the system. Configuration items are baselined when they have been formally reviewed by LMSI software engineers, database administrators, and if appropriate COTS representatives, and the HANDI 2000 Software Change Control Boards. These baselined items can be changed only through formal change control procedures.

\subsubsection{BASELINE IDENTIFICATION}

The LMSI software engineers, database administrators, and operations administrators, with support from the COTS representative, have the responsibility to provide a complete VDD prior to system implementation. The HANDI 2000 product baseline is the unique identification of all required components for a given application to function correctly. Listed below are examples that depict the type of structural identification required for traceability and change control, but are not inclusive.

- COTS Documentation

- System Change Requests

- System Design Document

- Test Plans

- HANDI 2000 Source Code

- Database Libraries

- Structure Query Language Scripts

- Processes

- Reports

- Parameter Files

- Operating Utilities

- Etc.

LMSI software engineers, database administrators, and operations administrators will maintain the current production and previous version of each system. Between baselines, each change to an individual system component will be tracked. The VDD identifies system components created by LMSI staff and the COTS software. For example, the VDD shall contain the appropriate version of the Database Management System software, the Operating System, Reporting Software, etc. Often in dealing with COTS products, it is not only the version that must be specified but also specific values or parameters specified. The data values are appropriately noted in the VDD if they affect or prevent normal system functionality.

\subsection{SYSTEM CHANGE REQUEST PROCESS}

The purpose of an SCR is to document requested changes to a baseline system. An SCR is required when a change is proposed to any component of the system. Reference APPENDIX B, HANDI 2000 Customization Guidelines and HNF-2639, Release and Upgrade Procedure

Some sample situations requiring an SCR are as follows:

- New tables need to be added to the existing system as part of a system enhancement to increase capabilities.

- Data elements need to be added to tables, or changes made to existing data tables.

- Changes to processing logic or the addition of new functionality.

- New screens/panels, or forms, are required for report definition and selection criteria. 
- Reports need to be added or changed.

- New system interfaces or modifications to the existing system interfaces are required.

- New or revised field calculations contained in screens or reports are required.

- Changing/Upgrading a COTS product.

\subsubsection{SYSTEM CHANGE REQUEST INITIATION}

Any HANDI 2000 end user, technical staff, computer systems support, etc. can initiate an SCR. The SCR may use an automated or manual tracking system. The SCR is provided to the FDH Project Manager for review. Reference APPENDIX C, System Change Request Form and Instructions

\subsubsection{SCR VALIDATION}

The FDH Project Manager reviews the SCR for apparent need with business analysts and LMSI software engineers, and if appropriate, consults with the COTS representative for a non-customized solution. If a non-customized solution is identified and acceptable, the solution is documented, implemented and the SCR is completed. If the solution requires customization, the SCR is provided to the FDH, LMSI, and COTS technical staff for alternative analysis and estimation of hours and cost.

\subsubsection{ALTERNATIVES ANALYSIS AND ESTIMATION OF HOURS AND COST}

Using the requirements contained within the SCR as a basis, the FDH, LMSI and COTS representatives identify possible alternatives. An estimate for man-hours is prepared. If a dollar amount is requested, LMSI finance will provide the appropriate figures. Additionally, costs for hardware or software, if needed, must be provided by LMSI's Business Operations office. As part of the estimate, and as appropriate to the SCR, the required deliverables for documentation, review, software construction, and testing are noted. The nature of these deliverables is directly dependent upon the technical scope and technical complexity of the SCR. System documentation will be revised as appropriate based on the amount of system change. Reference LMSI OSSP Cost Estimating.

\subsubsection{TECHNICAL REVIEW BOARD}

The TRB reviews all SCRs when the initial estimates reveal a change in work scope or costs to HANDI 2000 project. The SCR is provided to the HANDI $2000 \mathrm{CCB}$ with action recommendations from the TRB for approval/disapproval. Reference Section 2.4.1 of this document for detailed information.

\subsubsection{CHANGE CONTROL BOARD}

The Change Control Board will review SCRs provided from the TRB for approval/disapproval. Reference Section 2.4.2 of this document for detailed information.

\subsubsection{SOFTWARE DESIGN, CONSTRUCTION, AND UNIT TESTING}

HANDI 2000 will establish system environments as identified in the HNF-2584, Region and Database Management Plan. At a minimum, the test and production environments will reside on different hardware platforms. These environments will be used to develop, unit test, and perform acceptance testing of system changes.

An overview of the process is described here:

- A "Development" environment for the initial construction and debugging of software is maintained and controlled by the responsible software engineer. This area will include the modules necessary to affect the changes required by the SCR, as well as other accompanying programs and routines that are necessary for the particular construction activities being pursued. 
- After code changes are complete, the individual software engineer will perform their own debugging and unit testing activities, and if appropriate hold a code walkthrough before moving the software to the "Test" environment. Reference LMSI OSSP Code Walkthroughs.

- The "Test" environment will utilize production versions of all modules not being changed and will replicate as closely as possible the "Production" environment. Therefore, the modules not being changed will be migrated to the test environment, while the changed components will be copied from the development environment to form a complete system.

- Documentation of software revisions is maintained within the LMSI applicable program's source code, not the COTS source code. The program revision log is stored within the applicable program source code itself; that is, a description of the change, the SCR number authorizing the change, and the date of the change is recorded at the beginning of the source code for each individual component.

- An authorized LMSI person, under the direction of the FDH Project Manager, will update the appropriate documentation, such as the System Change Request, Software Design Description, System Test Plan, and if appropriate the System User Manual. The current version of the documentation will be "Checked-Out" of the FDH Configuration Management Library, and when the update is complete the new document version will be "Checked-In" to the appropriate library. FDH will then release the document in accordance with the $H N F$ PRO-244, Engineering Data Transmittal Requirements.

- Peer Reviews will be scheduled and conducted. Peer Reviews may or may not require the presence of FDH Internal Audit or LMSI System Quality Assurance. Reference LMSI OSSP Peer Review.

- Acceptance testing is accomplished in conjunction with FDH specified users, LMSI software engineers, and if appropriate COTS representative. The acceptance. will be documented in the test plan. Once the change has been accepted the SCR is updated and scheduled for implementation. If appropriate, the PRRB will approve/disapprove the implementation.

\subsubsection{PRODUCTION IMPLEMENTATION}

The LMSI software engineers maintain a list of all program modules affected by the SCR being worked, and updates the SCR with all changes performed. When the Test Plan has the appropriate signatures for acceptance, the TRB reviews to verify the change is ready for implementation. FDH and LMSI provide documentation to the PRRB to review for implementation approval. If approved, the responsible LMSI software engineer, database administrator, and/or operations move the software from the test environment to the production environment. The software and documentation are "Checked-In" and become part of the production baselines. This SCMP becomes effective as of this document's acceptance and will be reviewed throughout the HANDI 2000 life cycle and will be updated to accommodate the transition from implementation to operation maintenance as required. Reference $H N F$ 2795, Production Rollout Plan. After production implementation, LMSI will work to LMSI OSSPs. 


\subsection{EMERGENCY CHANGES}

In some instances, applications require immediate fixes to ensure user objectives can be met. In these cases it is unrealistic to try to rush a change through the HANDI 2000 Change Control Boards and the SCR process described above. Therefore a substitute process will be allowed in emergency situations.

\subsubsection{EMERGENCY CRITERIA}

A system emergency is defined, as any circumstance causing system interruption, a significant reduction in system functionality, or a critical system function has been impaired to the degree that the users can no longer achieve their business objectives. System downtime, major loss of functionality, or severe impacts to dependent or interfacing systems would be considered emergency situations. Improperly estimated schedules or customer driven changes to timelines are not considered emergencies. The TRB will review each emergency change and identify corrective actions to the software support project manager. In order to avoid nullifying the normal SCR process and SCM procedures, only emergency changes as defined here will be permitted.

\subsubsection{EMERGENCY CHANGE PROCESS}

In the event that an emergency change is required, the LMSI person requesting the change will complete the following process:

- Software engineer verifies emergency exists

- Software engineer opens an SCR and documents the emergency

- The change to the software is performed as expediently as possible

- Software engineer and/or database administrator moves the changed software into production, the SCM baseline is not updated

- The SCR is turned over to the project manager the next workday

- The software support project manager and software engineer will identify the long term fix and initiate the normal SCR process

\subsubsection{SCR FOLLOW-UP}

The designated LMSI software engineer, database administrator, and/or operations administrator retain the responsibility of ensuring the emergency change is routed through the normal SCR process and a permanent fix is implemented. The designated LMSI personnel will utilize normal management channels to ensure the appropriate actions are taken to maintain the SCM baseline synchronization with the production version.

\subsection{CONFIGURATION STATUS TRACKING}

Configuration Status involves the tracking and reporting of the change process. The goal is to maintain a record of all items in the baseline and provide traceability of all changes to the baseline through out the lifecycle. COTS baseline products will not be tracked beyond version numbers. Since LMSI has no ability to control the elements of a COTS package, no attempt at managing vendor changes between versions will be attempted. However, a list will be maintained of all COTS products and versions used by applications supported by LMSI. The LMSI designated personnel will coordinate with Software Accountability to ensure that at least one copy of each COTS product is retained until no longer needed. 


\subsection{DATA MANAGEMENT}

Data management is defined by functional elements that govern data planning and administration, data ownership, data analysis, and database administration. Data management provides for data that is consistent, complete, accurate, accessible, available and retrievable throughout the lifecycle of HANDI 2000. It is a process that produces quality data as the product from which information can be created for making business decisions. Data management changes will utilize the SCR process. Reference HNF-2585, Data Management Plan

\subsection{CONFIGURATION AUDITS}

The HANDI 2000 is primarily an integration of commercial products running on site standard equipment. FDH Internal Audit will conduct audits from an annual audit plan approved by DOE-RL and FDH. Management reviews are also performed upon request. Parts, or all, of HANDI 2000 may be the subject of such audits or management reviews. An audit survey is performed from which specific scope, object, and audit procedures are defined. Audit findings will be documented and completion dates for the deficiencies will be established. Reviews will be held to assure deficiencies have been corrected and incorporated. System audits generally include, at a minimum, the following audit areas:

- Physical electronic security

- System Documentation

- User Documentation

- User Training

- Change Control Process

- Data Integrity

\subsection{SECURITY ACCESS CONTROL}

HANDI 2000 contains data of a sensitive nature and the FDH, LMSI and COTS representatives will define security definitions and access profiles with appropriate levels. The LMSI database administrator is responsible for setting up the various network access safeguards. These safeguards prevent unauthorized access to the designated database servers and the data contained within. Reference HNF-2712, Security Administration Plan.

The use of passwords is extensive. Passwords are required to connect to the HLAN network and to access HANDI 2000. HLAN passwords are administered LMSI Network Support and the HANDI 2000 passwords are administered through user security features of the COTS application software. LMSI Customer Technical Service is responsible for setting up, monitoring, and disabling accounts on the HLAN upon notification from the FDH HANDI 2000 administrators. LMSI System Administration Staff, at the request of the designated FDH personnel, will establish new users of the appropriate HANDI 2000 system components and assign an initial password. End users will be able to modify their own passwords.

\subsection{BACKUP AND RECOVERY}

Arranging for and ensuring the adequacy of the system backups is the responsibility of the HANDI 2000 FDH Project Managers. The LMSI support service provider is responsible for managing and executing backup and recovery functions.

As a minimum, the plan cover the following computers:

- HANDI 2000 Indus PassPort and PeopleSoft Financials Production server

- HANDI 2000 Indus PassPort and PeopleSoft Financials Non-Production server

- HANDI 2000 PeopleSoft Human Resource/Payroll Production and Test servers

- HANDI 2000 Application Client Executables NT Fileservers

- CA Unicenter NT servers 


\subsubsection{BACKUP}

All computers specified in the backup, recovery, and disaster recovery document will be backed up to tape according to the business and technical requirements for each computer. The backup requirements for each computer will cover the backup strategies, backup schedules, and the tape retention schedules. Reference HNF2858. Backup and Recovery Plan for HANDI 2000 Software

Some of the potential backup strategies, specified in the requirement document are:

- Full tape backup

- Incremental tape backup of changes from the last full or incremental backup

- Differential tape backup of changes since the last full backup

- Backing up databases straight to tape

- Dumping databases data and/or logs to disk files and backing up the disk files to tape

Each computer will use appropriate backup strategies to meet the requirements of the business and technical processing needs on the computer. Any of the backup strategies that meet or exceed the backup requirements for the computer can be used.

Some of the potential tape retention schedules, specified in the requirement document are 7 days, 2 weeks, 4 weeks, 29 days, 32 days, 5 weeks, 6 weeks, one quarter, half year, one year, and multiple years. Each computer will use appropriate tape retention schedules to meet the requirements of the business and technical processing needs on the computer. Any of the tape retention schedules that meet or exceed the backup requirements for the computer can be used.

Some of the potential backup schedules, specified in the requirement document are:

- Fixed schedules: yearly, quarterly, monthly, weekly, certain days of the week; once a day, multiple times a day

- Dynamic schedules: at the start of batch processing, at the end of batch processing, at the start of critical processing, at the end of critical processing

Each computer will use appropriate backup schedules to meet the requirements of the business and technical processing needs on the computer. Any of the backup schedules that meet or exceed the backup requirements for the computer can be used.

\subsubsection{RECOVERY}

The FDH customer will notify LMSI Customer Technical Support in the event of a user workstation system failure or the network failure. Users will not experience any data loss except the current entry or modification data, which was being entered at the time of failure. In the event of unrecoverable, extreme server system failure, it may be necessary to recover to the latest tape backup or dump to disk, causing a loss of any updating that had occurted since the backup and failure. Reference HNF-2858, Backup and Recovery Plan for HANDI 2000 Software

\subsubsection{DISASTER RECOVERY}

HANDI 2000 infrastructure is designed so that if one of the computers is destroyed that there is a backup computer. For some of the computers, the fail-over to the backup computer is automatic. For other computers, the fail-over to backup computer is manual. There are shared disk storage systems in HANDI 2000 that do not have a backup share storage system. If one of these shared disk storage systems are destroyed, than the shared disk storage system would have to be replaced as expediently as possible. Reference HNF-2859, Disaster Recovery Plan. 
Most of the computers are located in the 339A building in the 300 area. If there were a disaster that affected the $339 \mathrm{~A}$ building, then the $339 \mathrm{~A}$ building would need to be fixed in a timely manner or a new location would need to be found for housing computers and the destroyed computers replaced. If the tape backups in the $339 \mathrm{~A}$ building were destroyed, then the backup tapes stored elsewhere would need to be used. The data lost and needing to be recreated would correspond to the number of days since creating the latest backup tapes stored elsewhere were created. 


\section{VERSION CONTROL}

\subsection{VENDOR VERSION CONTROL}

Each HANDI 2000 COTS product incorporates the vendor's unique product name, version number and release number. The HANDI 2000 INDUS integration vendor will manage, coordinate and document the HANDI 2000 COTS modules, products, and their relationships by providing the production ready releases to FDH.

\subsubsection{VENDOR VERSION IDENTIFICATION}

Version identification of the vendor products that comprise the HANDI 2000 system will be identified and certified by the Integration Vendor under the direction of the PHMC HANDI 2000 Project Manager as part of their contract. This includes the following:

- Unix

- Oracle

- Indus PassPort modules

- PeopleSoft modules

- P3 integration components

- Other integrated modules/products

\subsection{CUSTOM SOFTWARE VERSION CONTROL}

Customization to the PP and/or PS baseline products will be handled by numbering the system in a specific manner. All systems under HANDI 2000 control will follow this version numbering convention. Changes to the system shall be tracked by noting changes to the HANDI 2000 unique system version number. Therefore, by knowing the version number, database administrator(s) will be able to recreate the system for any given release.

\subsubsection{HANDI 2000 CUSTOM VERSION NUMBER FORMAT}

If the COTS product is customized, by FDH direction, then a unique HANDI 2000 version number will be applied to the change. The unique version number will always contain a prefix of " $\mathrm{H}$ ", the vendor version number, and an affix of a sequential alpha, i.e., Vendor version number $=$ PS7.0.1 and the customization version number $=$ HPS7.0.1a. The highest alpha letter will always be the most current version of the customized software and will be the one in production. No version number will be assigned until the software is tested and approved for implementation. Reference HNF-2585, Data Management Plan

The client-server environment of HANDI 2000 is composed of three distinct portions that require independent configuration control: the "front end" (client) portion, the "back end" (server) portion, and the report portion. Each can be independently modified as a result of some particular SCR without affecting some other portion of the architecture. For example, functionality updates affect the client software and may or may not affect any of the server software. Meanwhile, server software changes usually require some matching changes in the client software, but may not always do so. Consequently, version control and configuration management of client software is independent of server software. This may result in a different version numbers for the respective portions of the architecture. 
HANDI 2000

DOC ITEM: Software Configuration Management Plan

HNF- 2583, REV 0

DATE: $05 / 19 / 98$

\subsubsection{DOCUMENTATION VERSION CONTROL}

COTS documentation is controlled by the vendor, but FDH management and the LMSI technical support will maintain a library of all HANDI 2000 documentation, correspondence, vendor material, and project produced documents. The library will maintain the most current version of all documents throughout the lifecycle of the HANDI 2000 system. In addition, FDH will provide HNF numbered documents to the Hanford Document System.

If there is a baseline customization to the COTS product, then FDH with support from LMSI will be responsible for document version control concerning the customized portion of the system. The LMSI technical personnel will maintain an electronic copy of document in a controlled environment. In addition, the data administrator will maintain user and system documentation with an assigned HNF number in a restricted access database. When a change is required to the user and/or the system document it will be retrieved, changed, and a new version number will be assigned to the HNF number. A hardcopy of this revised documentation, with the new version number, will be transmitted to FDH Document Control through the used of an Engineering Data Transmittal. Reference HNFPRO-244, Engineering Data Transmittal.

\subsection{SOFTWARE RELEASE AND UPGRADES}

COTS Vendors other than INDUS may also ship releases, upgrades, bug fixes, etc. external to the HANDI 2000 integrated product. If appropriate, due to the FDH contractual agreement, the INDUS Integration Vendor will certify the item(s) is production ready. Custom release activities such as: Database Management Systems, Operation System upgrades, enhancements, corrections of logic defects, and application or system optimization changes are recommended to be released as a grouping or block point of changes. The FDH Project Manager and LMSI software engineer and database administrator will ensure that new releases and installation of HANDI 2000 software are tested prior to being placed in the HANDI 2000 production environment. Release/Upgrades will follow the SCR process. Reference HNF-2639, Release and Upgrade Procedure.

\subsubsection{RELEASE/UPGRADE PLAN}

For each release/upgrade a Release/Upgrade Plan will be generated. Listed below are items that should be identified in the Release/Upgrade Plan.

- Scope and schedule for general or maintenance upgrades

- System upgrade support

- All COTS software elements

- All tailoring and customization elements

- All operating system elements

- All desk top system elements

- All $3^{\text {rd }}$ party software elements

- All network system software elements

- All legacy systems elements

- All integrated systems elements that will be impacted

- Test environment

- Data migration approach

- Product tape fixes 
HANDI 2000

DOC ITEM: Software Configuration Management Plan

HNF- 2583, REV 0

DATE: $05 / 19 / 98$

PAGE: 20 of 28

\section{TOOLS, TECHNIQUES, AND METHODOLOGIES}

The tools, techniques, and methods used to implement SCM are usually discussed in terms of a (set of) libraries and the methods and techniques used to capture, store, and promote or release items of each type of library in a controlled manner. Reference HNF-2585, Data Management Plan and HNF-2584, Region/Database Management Plan.

\section{$5.1 \quad$ TOOLS}

- The PassPort Issues Log (ABACUS) will be used during the testing phase to record problems and track them through their disposition and correction.

- The Primavera P3 Scheduler will be used to track costs, tasks, resources, and schedule.

- Microsoft Visual Source Safe or Intersolve Project Version Control Software, or similar software will be used to control customized code versioning. If a software package cannot be procured in a timely manner a manual system will be used to control versioning. Reference Section 4.0, Version Control.

\subsection{TECHNIQUES}

\subsubsection{LIBRARY MANAGEMENT}

LMSI software engineers, database administrators, and/or operations administrators will manage operation and maintenance libraries.

- Programming Libraries - manage the changes to support software configuration

- Development Libraries - used by software engineers to develop and unit test code

- Integration Libraries - contains source code and executable load modules for integration testing

- Production Libraries - contains master copies of all support software configuration items and acts as backup for the run-time configurations used on the systems

\subsection{METHODOLOGIES/LIFE CYCLE}

The Commercial-Off-The-Shelf (COTS) based integrated system development lifecycle has emerged in recent years as the result of tremendous interest within the software industry in building reliable, cost effective, distributed software systems through the utilization of both generic and domain-specific COTS software packages. On-going COTS-based software development projects range from small single function to complex, large-scale software systems.

The buy and adapt approach is the method used for HANDI 2000. The buy and adapt model is characterized by acquiring a single complete working system that satisfies most of the requirements and adapting and extending it for desired needs. Adapting is completed by extending the system with add-ons, interfaces with another application, or modifications to the original source code. Each of these adaptive methods would be an application development project with its own lifecycle; an example is an added interface that is developed to fulfill a functional requirement to pass data from a project tracking module to a budget/staff forecasting module. The COTS solution is best suited for situations where changes to the COTS can be minimized. This means the customer is willing to accept the solutions as-is and is able to change business rules as necessary to adapt to the COTS packages.

The COTS development model follows a modified version of the waterfall lifecycle consisting of requirement analysis, implementation analysis, construction, testing, and implementation. The requirements and overall design are clearly understood before any other design or integration takes place. The application is broken into welldefined functional areas that can be fit with a COTS application. Each functional area is then evaluated for fit-gap to the COTS application, and the COTS application is evaluated for integration into the larger system. For HANDI 2000 production, reference LMSI OSSP, COTS LIFECYCLE and for HANDI 2000 Project, reference HNF-1948, Finance and Supply Management Project Execution Plan for HANDI 2000 Project Lifecycle. 


\section{DATA/RECORDS COLLECTION AND RETENTION}

The FDH HANDI 2000 Project Managers shall be responsible for determining record retention schedules, with the assistance from LMSI technical staff. HANDI 2000 system development and maintenance records will be processed in accordance with the following procedures:

HNF-PRO-210, Records Management Program

HNF-PRO-214, Record Inventory and Disposition, Schedules

HNF-PRO-215, Records Storage, Retrieval, and Destruction

HNF-PRO-222, Quality Assurance Records

HNF-PRO-231, Records Schedules 


\section{APPENDIX A Version Description Document Format}

1.0 Project Identification - This paragraph shall contain the project version identification number for the application to which this document applies. (I.E., ISEARCH 1.1) The initial baseline release for applications in production shall assume the existing version number for the application. If no number exists the initial baseline will assume a version number of 1.0. All applications shall be numbered in accordance with the SCM plan.

1.1 System Overview - Provides a brief overview of the application's purpose, user community, and intended functionality. (I.E., The ISEARCH application provides the Hanford community with search, retrieval, viewing, printing, and mail capabilities with regard to Hanford documentation, drawings, and record material.)

2.0 Referenced/Related Documents - This section identifies referenced documents as well application specific documentation. (I.E., ISEARCH SRS HNF-000458)

\subsection{Version Description}

3.1 Software - This section identifies the CM baseline directories, which contain the application software created and maintained by this organization. Assigned by CM personnel prior to baseline creation. This includes any script or report definition files necessary to maintain, execute, install, or in any way support the application.

3.2 Database - This paragraph identifies the supporting DBMS, including version number, and the implemented Database Version number. The $\mathrm{CM}$ baseline directory containing database definition language, script, or defining module will be also be referenced. (I.E., Server then directory - CMSRVR01/ISEARCH/DB)

3.3 Operating System and Environment - This section will identify the system, operating system, and peripheral environmental specifications under which this software was designed to operate. (I.E., NT 5.0 Server with SQL 6.5, Min 128 Mb RAM, 16 GB Available contiguous Disk Space.)

3.4 COTS - This paragraph lists any COTS products, including version or release, used to support the application in a production mode. (1.E., Altris 11.1, Crystal Reports 3.0).

3.5 Metadata - This section details any parameters, option settings, or specific data values that may affect the performance of, or prevent the use of the application. (I.E., Compiler options, Security Settings, Data values driving application functionality, etc.)

3.6 Notes - This paragraph is used to convey any additional information about the application, its installation, execution, or interface requirements. (I.E., File or directory locations supporting input/output functions, known limitations/problems, etc.)

4.0 Change Description - This section is used to define the intent of the VDD. (I.E., Establish an initial baseline or implement a new release) Changes from one version to the next should be described briefly here and system change request numbers referenced.

5.0 Installation Instructions - This section describes the installation of the application in sufficient detail to allow the application to be installed from the CM baseline files. 


\section{APPENDIX B HANDI 2000 Customization Guidelines NOTE: As of 05/18/98. Appendix B is still under review.}

The HANDI 2000 Customization Guidelines document is intended to cover the implementation phase of the HANDI 2000 Project. This document will be reviewed throughout the HANDI 2000 life cycle and will be updated to accommodate the transition from implementation to operation maintenance as required. All sophisticated COTS products require some level of change, or customization, to adjust to the specific needs of a customer. In the case of PeopleSoft products the average is $10-15 \%$ of all of the screens, reports, processes, etc., INDUS maintains that PassPort products require less customization than PeopleSoft, and $\mathrm{P} 3$ asserts that their product requires no customization. The delivered products may require some level of change to support the customer's business decision on how to use the COTS product.

This customization guideline is to help define and control, during the implementation phase, changes to the baseline products. After going into production with the COTS modules the System Change Request process supercedes this guideline.

Technical Impact

Low - indicates that there is little or no impact to the system or processes and there will be minor efforts required to maintain the modification. Creation and modification of operator groups, stored procedures, indexes, menus, reports, views and triggers should be included here. Changing the values of delivered fields not utilized outside of the executable product and modifications of the data access model would be considered low technical impact.

\section{Low Technical Impact Examples}

Creating two new tables to support Training plans should be considered "Low". These new tables are almost always queried with data that is needed in other tables within the same software module. The tables are not considered core, and the software upgrade routines would not detect them, if certain table naming conventions are adopted. Adding alternate search keys for retrieving data within the application is considered "Low". This change is not detectable outside the system and provides alternate means of quickly retrieving data that more closely match the user's business processes.

Adding data fields that provide more information about courses would be considered "Low". This information is not tracked outside of the originating system. The data is used on custom and ad-hoc reports needed by the user.

Moderate - indicates that there are some core tables or processes that have been touched and that a complete system test should be done. Additionally, a moderate rating indicates that during each upgrade the modification should be revisited and re-tested for system changes.

\section{Moderate Technical Impact Examples}

Adding additional fields to the Job Table to support the Training organization should be considered "Moderate". The Job table is considered a core table, but the new fields are not processed outside Human Resource Information System (HRIS). If a delivered column in the Job Table were modified, this would be classified as a complex customization.

Creating a process to recover incurred costs for training classes has an effect on another software product outside of the originating system (HRIS to Financials). While not a core process table in HR, it would need to be coordinated with the financial system to insure that the modification can correctly recover costs using the delivered Financials module. While not core in HRIS, this type of data is tracked and has associated logic in more than one software module. 
Creating additional data fields to identify area, building and room data for an employee is considered a "Moderate" impact. The data fields reflect the interface requirements of dozens of external systems, and are not referenced in the processing logic of PeopleSoft or Indus software, since they previously did not exist.

Complex - indicates that core complex tables and core processing were modified. The maintainability would be high because the vendor would no longer support the module and processing. Additionally, a complete review and possible re-write would be required during each update or system update. All delivered COBOL modifications would be considered "Complex".

\section{Complex Technical Impact Examples}

Changing the width and attributes of a key identifier field would be considered complex. This field is used throughout the system, as well as in other integrated software products. Processing logic that references key fields is extensive and may not work correctly in all tables as a result of this modification. Changing widths and attributes of other major employee, financial or supply categorization fields that are used extensively outside the originating software executable would also be complex customizations. Changing the Pay Calculation Cobol routine would be complex.

Adding a separate organization code strictly to support financial organizational costing a rollup to the Department Table would be considered "Complex". This data field would have to be referenced in a large number of modules within Financials and PassPort, which would require customizations.

Changing the method that payroll costs are collected and allocated would be considered "Complex". This change significantly affects other integrated modules in the Financials and PassPort product line.

\section{Business Priority}

Low - Important need, but less efficient or more costly manual processes can accomplish the same task.

Medium - Task required by management, supports new non-critical business process.

High - The change must be done or the mission critical task can not be accomplished.

\begin{tabular}{|c|c|c|}
\hline $\begin{array}{l}\text { Technical } \\
\text { Impact }\end{array}$ & $\begin{array}{l}\text { Business } \\
\text { Priority }\end{array}$ & $\begin{array}{l}\text { Review / Approval } \\
\text { Level* }\end{array}$ \\
\hline Low & Low & Project Manager \\
\hline Low & Medium & Project Manager \\
\hline Low & High & Project Manager \\
\hline Moderate & Low & Project Director \\
\hline Moderate & Medium & Project Director \\
\hline Moderate & High & Project Director \\
\hline Complex & Low & $\begin{array}{l}\text { HANDI } 2000 \text { Change } \\
\text { Control Board }\end{array}$ \\
\hline Complex & Medium & $\begin{array}{l}\text { HANDI } 2000 \text { Change } \\
\text { Control Board }\end{array}$ \\
\hline Complex & High & $\begin{array}{l}\text { HANDI } 2000 \text { Change } \\
\text { Control Board }\end{array}$ \\
\hline
\end{tabular}

*Note: Regardless of technical impact or business priority, if the change affects another product family (i.e. an HRIS change that would affect Financials), it must be approved at least at the Project Director level. 


\section{APPENDIX C SCR - System Change Request Form Instructions}

SCR Number:

Project ID: Activity Type: Software Change Problem Report

Sub Project ID: Type Change:

Title:

Description:

Module Name(s):

Resolution:

Status: Priority:

Urgency:

Requester:

Request Date:

Request Completion Date:

Comments:

WBS code: Assigned To:

Acceptance

Criteria:

Est Begin Date:

Est End Date:

Est Hours:

Act Begin Date:

Act End Date:

Act Hours:

CCB Date:

Closed Date: 
SCR Number - Each Project can pre-set its starting number and each System Change Request will require a unique number for each Project. This number is used for tracking the SCR. The automated SCR system will automatically generate the SCR Number.

Project ID - The Project ID associated with this request (i.e. HANDI 2000, TIS, HUB, etc).

Activity Type - Select either System Change or Problem Report.

Sub Project ID - The Sub Project ID is a further breakdown of Project ID information. For example, a Project ID might be HANDI 2000, and a sub Project ID might be General Ledger.

Type Change - Identifies whether the record is a defect of enhancement.

Title - The title associated with this SCR or PR.

Description - The requirements associated with the SCR or PR. It may contain the customer's and/or software engineer's requirement descriptions.

Module Name(s) - Any modules changed by the SCR. For each SCR there could be many modules affected and these should be individually identified.

Resolution - Description of the solution used in solving this request.

Status - The only values allowed within this field are: New, Cancelled, Accepted, In Work, User Test, Ready to Implement, Completed, or On Hold.

Priority - The software engineer will determine the criticality of the SCR or PR to the project, (i.e., 1- System or major component down/unusable through 10 - Slight modification needed)

Urgency - The requestor would indicate the urgency of the SCR or PR. Three choices can be entered into the field: 1 - High, 2 - Medium, or 3 - Low.

Requester - The name of the individual making the request.

Request Date - Date the request was made.

Requested Completion Date - Date the requester would like the request to be completed.

Comments - This is for the comments made thought out the life cycle of this request.

WBS Code - The Work Breakdown Structure Code associated with the SCR or PR. The Project must have a WBS Code in order to perform the work.

Assigned To - The name LMSI/SD\&I software engineer who is assigned to the SCR or PR.

Acceptance Criteria - Acceptance criteria specified by the Requester.

Estimated Begin Date - Estimated Begin Date for work to begin on the SCR or PR.

Estimated End Date - Estimated End Date to complete work on the SCR or PR. 


\section{APPENDIX D HANDI 2000 Board Members}

As of 05/05/98

- TECHNICAL REVIEW BOARD

S. L. Bennion, FDH - Chair Person

D. E. Adams, FDH

K. K. Friday, FDH

P. B. Isaacs, LMSI

K. Whiteaker, INDUS

A. H. Wirkala, DOE-RL

- CHANGE CONTROL BOARD

E. W. Penn, Jr., FDH - Chair Person

R. E. Gates, FDH

S. E. Manley, FDH

A. Q. Murphy, DOE-RL

A. H. Wirkala, DOE-RL

- PRODUCTION READINESS REVIEW BOARD

R. E. Cartmell, LMSI - Chair Person

B. D. Elison, LMSI

D. L. Fischer, LMSI

D. E. McElroy, LMSI

R. R. Petro, LMSI 